\title{
专访催化领域代表人物一一王双印教授
}

\author{
《物理化学学报》编辑部
}

北京大学化学与分子工程学院, 北京 100871

\section{Interview with the Leader of Catalysis: Prof. Shuangyin Wang}

\author{
Editorial Office of Acta Physico-Chimica Sinica \\ College of Chemistry and Molecular Engineering, Peking University, Beijing 100871, China. \\ Email: whxb@pku.edu.cn \\ Published online: November 11, 2020.
}

催化领域的发展对于解决人类社会的环境、能源等重大问题起到至关重要的作用。催化体系、催化 剂是催化领域发展的关键。研究催化剂结构、理解催化反应机理、剖析结构与性能之间的构效关系、设 计高性能催化剂来满足工业化应用是催化领域研究的核心内容。随着人类能源危机和环境污染的不断加 剧, 开发绿色可持续新能源催化技术是解决上述问题的关键策略。

本期我们有幸采访了国内催化领域的代表人物, 《物理化学学报》编委王双印教授, 为我们分享了 他的研究经历及对国内外催化行业的分析。

问题 1：请您为读者们简单介绍一下您的科研历 程。

回答: 我在浙江大学化工系本科毕业设计论文从 事的是高分子材料方面的研究工作，2006年到新 加坡南洋理工大学攻读博士学位从事燃料电池方 面的研究, 随后在美国凯斯西储大学、德克萨斯大 学奥斯汀分校、英国曼彻斯特大学(玛丽居里学者) 开展研究工作。2013年入职湖南大学, 主要从事电 催化剂缺陷调控, 燃料电池以及有机电催化转化 等方面的研究工作。

问题2: 是什么把您吸引到催化的研究领域的呢?

回答: 进入催化领域, 是件很偶然的事情。我博士 期间的第一个课题是燃料电池质子交换膜的表面 修饰, 利用高分子通过静电自组装的方式对质子 交换膜进行表面修饰, 抑制抗甲醇穿梭的性能。在 课题研究过程中, 偶然发现所使用的高分子可以 高效地修饰碳材料, 用其负载贵金属纳米颗粒的 时候, 可以很好地提高纳米颗粒的分散性, 并提升
其负载量, 对甲醇氧化显示了很好的电催化性能。 这一偶然发现, 使得自己从高分子膜方向转向了 电催化研究。

问题3: 中国催化的研究在国际上处于什么位置?

回答: 在国家的大力支持下, 我国催化领域的研究 发展迅速, 成果显著。在全方位、分层次的战略布 局情况下, 经过多年来长期的奋斗, 我国催化领域 已形成了一支高水平的基础研究队伍, 取得了一 批国际上有影响的成果, 整体研究水平已进入世 界先进行列。近年来, 国内研究学者在催化这一领 域取得了巨大发展, 先后提出了研究催化的新视 角、新材料、新反应体系。催化研究领域涉及面广, 在各个方面都取得了巨大进展。以催化新材料的 研究为例, 中国科学院大连化学物理研究所张涛 院士的团队原创性地提出了单原子催化剂的概 念, 单原子催化剂现已被国内外研究者广泛应用 于热催化、电催化以及一些重要的工业催化过程 (例如水煤气变换反应和甲醇重整), 显示优异的催 化活性和选择性。 
问题 4: 目前催化领域的发展存在的最大的挑战有 哪些? 未来有哪些发展趋势?

回答: 较大的挑战有很多, 主要包括明确催化剂微 观结构与催化性能之间的关系, 寻找催化活性与 稳定性俱佳的高效催化剂, 还有跟踪催化剂表面 原子与反应分子及其中间体的相互作用及变化过 程, 以及在复杂环境中研究特定化学反应的催化 过程等。总体来说, 深入理解催化反应过程中反应 物与催化剂的动态变化以及开发出可用于工业生 产的高性能催化剂是目前最大的挑战。未来催化 剂的机理研究更注重原位表征技术的运用, 各种 催化反应体系的交叉和结合会大大增加, 对催化 剂的性能将会更注重实际工况下的评估。

问题5: 请您列举一些您课题组现阶段主要的研究 方向和学术成果。

回答: 我的课题组现阶段的研究方向主要包括: 电 催化剂缺陷化学, 有机电催化合成, 高温然料电 池。在基础研究方面, 我们开辟了“电催化剂缺陷 化学”方向, 主要从理解缺陷-构筑缺陷-利用缺陷 的视角开展研究工作, 在这一领域取得了系统性 创新研究成果: (1)自主搭建微区电化学平台, 明 确了边缘缺陷碳的高活性, 建立了碳本征缺陷-催 化活性-表面电荷之间的构效关系; (2)实现了缺陷 的选择性构筑, 揭示了化合物缺陷催化机制, 为高 性能电催化剂的设计提供了理论支撑和技术指 导; (3)利用缺陷位的活泼特性, 实现了缺陷位的 功能化修饰, 赋予了催化剂新的催化功能, 丰富了 缺陷化学研究的内涵, 为催化剂缺陷调控提供了 新的思路。在应用研究方面, 我们开发了负载型催 化剂的批量、普适化制备工艺, 为工业催化、燃料 电池以及清洁能源生产等领域催化剂的应用提供 了空间。在有机电催化转化方向, 我们成功实现常 温常压下电催化合成尿素, 提出了亲核试剂电催 化转化的氢缺陷循环机制。

问题6: 您认为催化发展和应用对我们的社会、环 境和经济会有哪些影响?

回答: 随着社会快速发展, 人类对能源的需求不断
增加, 化石能源的过度消耗也造成了严重的环境 污染和能源危机。提高能源利用效率和开发新能 源是解决环境污染和能源危机的有效途径。尤其 是新能源电转化装置因其高效清洁等优势得到了 科学家们的广泛关注。其中涉及的反应包括氧还 原反应(ORR), 析氧反应(OER)和析氢反应(HER)、 二氧化碳还原 $\left(\mathrm{CO}_{2} \mathrm{RR}\right)$ 以及氮气还原 $(\mathrm{NRR})$ 等。而 这些电化学反应都需要催化剂才能够高效进行。 催化材料是解决能源危机中的重要核心技术, 理 解催化机理、掌控催化活性位点、调节催化材料中 的电子、离子的传输及其与反应物和产物分子的 相互作用对提高催化剂的催化效率、选择性和耐 久性等方面都起着重要作用。因此, 对于实现低能 耗、零排放、清洁化生产等一系列目标来说, 催化 发展对于当今社会的可持续发展具有重要意义。

问题7: 您认为科研人员最重要的品质是什么? 您 对研究生或年轻的科研工作者有什么建议?

回答: 科研人员最重要的品质是好奇心和独立思 考, 科学研究过程有很多未知, 保持探索未知的渴 望并独立思考非常重要。对于有志从事科学研究 的青年学生或学者, 我有两点建议: (1) 夯实基础 知识, 探究科学本质; (2) 独辟蹊径, 忌盲从热点。

问题 8: 请问您认为什么是期刊发展最重要的因 素?

回答: 我认为期刊发展的最重要的是发表论文的 质量水准。为了吸引高质量的高源, 期刊需要关注 的点很多。首先是同行认可度。增强同行认可度的 主要方式是通过对发表内容进行仔细䇻选, 实现 对深度内容的挖掘, 对创新内容的拓展和对专业 发展方向的引导, 从而增进同行对于本期刊的专 业性与内容的严谨度的认可, 有利于本期刊学术 口碑的建立。其次是审稿人的专业匹配度。通过对 审稿人专业背景的严格挑选, 为每篇稿件挑选合 适的审稿人, 保证审稿人的专业背景能为稿件提 出既有深度又有广度的专业性意见与建议。然后 是稿件处理速度。当今社会科研工作发展迅速, 提 高稿件处理效率, 对于作者对其工作的进一步推 进和提升具有重要意义。 
王双印，“国家杰出青年基金” 获得者(2018年)，“湖湘青年英才”支持计划入选者 (2014年), “湖南省杰出青年基金” 获得者(2016年), “长沙市杰出创新青年培养计划”入 选者(2018年), 全球高被引科学家(化学、材料), 爱思唯尔中国高被引学者(化学)。现为 湖南大学二级教授, 博士生导师。2006年本科毕业于浙江大学化工系, 2010年在新加坡 南洋理工大学获得博士学位, 随后在美国凯斯西储大学, 德克萨斯大学奥斯汀分校、英 国曼彻斯特大学(玛丽居里学者)开展研究工作。

主要从事的研究方向为电催化剂缺陷化学, 高温燃料电池, 有机电催化。以第一作者/通讯作者已在 Nat.Chem.NAt.Commun、JACS、Angew.Chem.Adv.Mater、Chem等国际著名期刊发表SCI论文100余 篇, 论文他引 17000 余次, 所发表的SCI论文中影响因子大于 10 的高水平论文有 70 余篇, ESI高被引论文 的有 55 篇, 1 篇论文入选中国百篇最具影响力国际学术论文, H指数为 71 。王双印教授的科研成果获得 2019年度湖南省自然科学奖一等奖(第一完成人)、2019年度教育部青年科学奖(第一完成人)、2019中国 可再生能源学会科学技术人物奖等。担任Energy \& Environmental Materials副主编, Journal of Energy Chemistry的Section Editor, 《物理化学学报》编委, 《中国化学快报》青年编委, 中国颗粒学会青年理事, 《电化学》编委等。 